made, high-level radioactive wastes might be disposed of in the Earth - a nice irony considering that the sites under consideration have been shaped almost entirely by the heat from radioactive isotopes, albeit different ones.

To a great extent, isotope geochemistry is a matter of dating events and processes that have self-evidently taken place or have been shown to do so using other types of evidence. This has tended to give the topic a "service industry" image, which is perhaps another reason why would-be popularizers have concluded that it lacks glamour.
Ozima's considerable achievement in this book has been to demonstrate to laypeople and students the vitality, excitement and importance of isotope geochemistry as a subject in its own right. In this cause he has been helped beyond measure by Judy Wakabayashi, who has produced a beautiful translation that puts the majority of native scientific English writers to shame.

Peter J. Smith is Reader in the Department of Earth Sciences at the Open University, Milton Keynes, and editor of Open Earth.

\title{
Ultimate histories and final destinations
}

\section{John Noble Wilford}

Cosmic Dawn: The Origins of Matter and Life. By Eric Chaisson. Pp.302. ISBN 0-316-13590-9. (Atlantic Monthly Press/Little, Brown, Toronto: 1981.) \$14.95. Genesis: The Origins of Man and the Universe. By John Gribbin. Pp.360. ISBN UK 0-460-04505-9; ISBN US 0-4402832-9. (Dent/Delacorte: 1981.) £7.95, $\$ 13.95$.

IN content, purpose and intended audience (the educated layperson), these two books are much alike. Both cover the same ground, which is to say that they start with the big bang and bring us forward through the creation of the Solar System to the emergence of life and the ascent of man. But they differ considerably in style. Cosmic Dawn is an extended essay, instructive and literate, building toward a moving statement on the human condition and prospects. Genesis is a comprehensive exposition of current consensus and debate on our origins, tutorial in style but lively and often provocative.

Chaisson, an associate professor of astrophysics at Harvard, has produced a work of history as much as of science, with its narrative force and synthesis of grand themes. Astrophysicists, as he says, are the "ultimate historians". His essay is shaped around two "critically important transformations in the history of the universe"'. The first was the emergence of matter from radiation; the second, the emergence of technologically intelligent life.

$$
\text { The latter, he writes, }
$$

is the quintessential event in the development of matter, the threshold beyond which life forms can truly begin to fathom their role in the cosmos. Significantly, then, we have an obligation, a responsiblity to survive.

Michael Ruse's The Darwinian Revolution (reviewed in Nature 284, 670; 1980) has been published in paperback by Chicago University Press, price \$9.95 (US only).
To survive as a civilization Chaisson contends that we must circumvent the very real possibilities of overpopulation, selfdestruction, genetic degeneration and subjugation by computers. Long-term survival of the species, he states in an eloquent conclusion, may depend on our commitment to a two-fold programme of simultaneously colonizing the nearby planets, which he sees as a dispersal of the species so as to be less vulnerable to local catastrophe, and searching for galactic civilizations, which, if found, might reassure us that others have attained technological power and still avoided doomsday. The case for extraterrestrial exploration has rarely been better stated.

Gribbin, an astrophysicist and prolific science writer, also concludes with a forward-looking chapter, "Destinations", and suggests, among other things, the possibility of our descendants developing a "space culture". But, in general, his discussion of the future is unfocused and unsatisfying. This is a pity, for the rest of the book is so clear and rich in detail and insight. Much more than Chaisson, Gribbin spells out the discoveries and reasoning behind current thinking in cosmology and biological evolution. His discussions of plate tectonics, the origins of diversity and the origins of Earth are especially lucid. His style, like a gifted lecturer's, is by turns playful and authoritative. The index and organization by subheadings make it easy to refer back to subjects of particular interest.

Either book can be recommended to the student who seeks a broad understanding of the origins of mankind and the Universe (students of the humanities might prefer Cosmic Dawn), or to the general reader who wants a rewarding experience delving into the "ultimate" history.

John Noble Wilford is a science correspondent of The New York Times who specializes in space exploration. His most recent book is The Mapmakers (Knopf, 1981).

\section{Pressure to scale}

\section{W.D. Hackmann}

Barometers. By Bert Bolle. Pp.256. ISBN 0-85242-710-7. (Argus, Watford, Herts: 1981.) £12.50. Early Scientific Instruments. By Nigel Hawkes. Pp.168. ISBN 0-89659-192-1. (Abbeville Press, New York: 1981.) \$29.95.

COLLECTORS of antiques are becoming increasingly interested in scientific instruments. Sundials, telescopes, microscopes and barometers are amongst the most popular. Barometers, especially, have commanded wide interest because of their attractiveness as pieces of furniture. Bert Bolle, a Dutch antique-dealer, has been a barometer enthusiast for many years. His book, which was first published in The Netherlands in 1978, occupies a niche between the purely technical histories, such as that written by W.E.K. Middleton in his The History of the Barometer (Johns Hopkins Press, 1968), and those describing antique barometers, of which the best English example is N. Goodison's English Barometers 1680-1860 (Cassell, 1977).

The book is divided into three parts. The first describes the evolution of the various barometer types, and each chapter deals with a specific pattern: stick, marine, miner's or pit, sign-post, banjo and aneroid. Ancillary instruments, such as thermometers, hygrometers and psychrometers, are also discussed uriefly. Between 70 and 80 thermometer scales were in existence in the eighteenth century, and a Dutch example of 1754 with 18 scales is illustrated.

The earliest barometers were simple tubes containing mercury, based on Torricelli's well-known experiment of 1644 , to which Descartes added a scale four years later. At first, the arrangement was used to demonstrate the "weight of air", but there was a slow realization that it could be used in forecasting weather. Research shifted to England. Both Robert Boyle and Robert Hooke improved the design, and gradually during the 1680 s instrument-makers, clock-makers and opticians started to manufacture barometers for domestic use. Within a short period the main mercury barometer types were established. Trade concentrated in Britain, and to a lesser extent in The Netherlands, where a double or contra tube system (the contra-"bakbarometer") was invented by Huygens. Amongst the earliest makers were the famous clock-makers Thomas Tompion and Daniel Quare, then, during the eighteenth century, the manufacture of barometers became the speciality of expatriate Italian craftsmen; two of the best-known Victorian firms, Negretti \& Zambra and Pastorelli \& Rapkin, evolved in this way. In The Netherlands, too, Italian makers appeared in the 1750s. 